\title{
Culpables, millonarios e impunes: el difícil tratamiento del derecho penal del delito de cuello blanco*
}

\author{
Guilty, millionaire and unpunished: the difficult \\ criminal law treatment of white-collar crime
}

\section{Laura Zúñiga Rodríguez ${ }^{* *}$}

\section{RESUMEN}

Existen factores culturales en la sociedad que favorecen una comprensión de los delitos de cuello blanco mucho más benigna que la criminalidad callejera. Existe, por parte de la ciudadanía, los infractores y las leyes, una visión atávica de la peligrosidad de la delincuencia violenta, callejera, contra la vida y la propiedad, que se contrapone con una visión benigna de la criminalidad de los poderosos. El propio derecho penal se muestra inidóneo para comprender la amenaza social que supone la criminalidad cometida desde los sectores poderosos: corrupción política, corrupción privada, criminalidad corporativa, criminalidad financiera, etcétera.

PALABRAS CLAVE: Delito de cuello blanco, impunidad, criminalidad de los poderosos, criminalidad callejera.

\section{ABSTRACT}

It was possible to analyze cultural factors in the on-going society that favor a more benign comprehension of white-collar crimes than street delinquency. There is an atavistic vision of riskiness of violent, street crime, against life and property. The culture of the unbridled competition of the on-going productive model and the economic deregulation favor illegal acts. This paper proposes a necessary review of this conception, from criminal law.

KEY WORDS: White-collar crime, impunity, criminality of powerful people, street delinquency.

\footnotetext{
* Recibido: 6 de octubre de 2014. Aceptado: 24 de noviembre de 2014.

** Profesora titular de Derecho penal en el Departamento de Derecho Público General de la Universidad de Salamanca, España (Izr@usal.es).
} 


\title{
Sumario
}

1. Introducción: el delito de cuello blanco

2. Entre lo legal e ilegal

3. ¿Es un delito el delito de cuello blanco?

4. La percepción social de la criminalidad de los poderosos

5. La impunidad de los delitos de cuello blanco

6. A modo de conclusión: las dificultades en la persecución penal de los crímenes de los poderosos

\begin{abstract}
Los economistas suelen estar muy familiarizados con los métodos utilizados en el ámbito de los negocios, pero no están acostumbrados a considerarlos desde el punto de vista del delito. Muchos sociólogos, por su parte, están familiarizados con el mundo del delito, pero no están acostumbrados a considerarlo como una de las manifestaciones de los negocios. Esta conferencia intenta integrar ambas dimensiones del conocimiento 0 , para decirlo de forma más exacta, intenta establecer una comparación entre el delito de la clase alta - delito de cuello blanco- compuesta por personas respetables 0 , en último término respetadas, hombres de negocios y profesionales, y los delitos de la clase baja compuesta por personas de bajo status socioeconómico.
\end{abstract}

\section{Introducción: el delito de cuello blanco}

"Culpables, millonarios e impunes" es el título de un artículo aparecido en el suplemento económico de los domingos de El País, del 12 octubre de 2008, muy pocos meses después de la caída del Banco Lehman Brothers y de que 38 se desencadenara la crisis financiera actual. El artículo resaltaba cómo unos determinados comportamientos, realizados desde las cúpulas directivas de las empresas, han propiciado que estallen las burbujas bancarias e inmobiliarias que han desencadenado, cual efecto dominó, la mayor crisis económica del capita-

\footnotetext{
1 Éstas son las primeras palabras de la conferencia de Edwin SUTHERLAND en la reunión anual de la American Sociological Society, en Filadelfia, en diciembre de 1939, dando lugar al nacimiento del concepto de "delito de cuello blanco". El trabajo sólo sería publicado diez años después y luego de haber sufrido varias censuras por parte de las empresas objeto de observación de sus trabajos empíricos. Cfr. Álvarez-Uria, Fernando. "Prólogo", en Sutherland, Edwin. El delito de cuello blanco, La Piqueta, Madrid, 1999, pp. 11, 12 y 32.
} 
lismo después de la Gran Depresión. Concretamente, "el mal hacer de una casta intocable de directivos está detrás de la crisis financiera”. Las consecuencias de este colapso económico todos las sabemos: paro, pobreza, miseria, inseguridad, delincuencia, suicidios, etcétera.

Por supuesto que en ciencias sociales no es posible demostrar científicamente las causas y efectos de manera lineal de los fenómenos sociales, máxime en el momento histórico en que vivimos de globalización de la economía, en el que coadyuvan una serie de factores para producir determinados efectos. Pero tampoco se necesitan elementos de prueba notables para comprobar que, efectivamente, detrás de la quiebra de los bancos y las empresas que inflaron sus cuentas, de las calificaciones de las agencias de calificación encargadas de verificar si esas cuentas eran reales, existen comportamientos más que inmorales, rayanos en la criminalidad, dependiendo, claro está, de las tipificaciones de cada legislación. Más allá de la calificación jurídica, conviene evocar los hechos para verificar si son o no jurídico-penalmente relevantes.

Desde hace algún tiempo, los especialistas han destacado que los modelos empresariales, especialmente los que adoptan las formas jurídicas de sociedades anónimas, se han caracterizado últimamente por un aumento del poder de los directivos y su alejamiento del poder de decisión de los socios. Siguiendo el mismo reportaje:

[...] el capitalismo moderno ha emulado este sistema de castas. Sus brahmanes son los directivos y consejeros de las grandes corporaciones. Gozan de privilegios y prebendas por doquier: sueldos estratosféricos, planes de incentivos, vacaciones, jets privados y clubs de campo a costa de la empresa. Y no tienen casi ninguna responsabilidad [...] En caso de despido cuentan con cláusulas que les aseguran indemnizaciones multimillonarias, conocidas como paracaídas de oro (golden parachute), de los que no disfrutan los trabajadores, los parias de este orden económico [...] Sus arruinados accionistas y ahorradores o los trabajadores despedidos se preguntan por qué en lugar de ser reclamados por los juzgados, los ejecutivos han salido sin hacer ruido por la puerta de atrás y con las carteras llenas. Sólo las cinco mayores firmas financieras de Wall Street -Merrill Lynch, JP Morgan, Lehman Brothers, Bear Stearms y Citigroup- pagaron más de tres mil millones de dólares en los últimos cinco años a sus máximos ejecutivos. ${ }^{2}$

En efecto, el proceso de desregulación económica iniciado en la década de los ochenta, liderado por Ronald Reagan y Margaret Thatcher, ha dado lugar al desarrollo de un capitalismo financiero que despliega grandes pasibilidades para el

2 "Culpables, millonarios e impunes", El País, 12 octubre de 2008, p. 8. 
movimiento de capitales, para la especulación financiera y, consecuentemente, para amplios márgenes de ganancias que se mueven entre los límites de lo lícito, con muchas posibilidades de rozar lo ilícito. La desregulación financiera amplía los márgenes de lo lícito, dando el mensaje a los administradores de sociedades que es posible arriesgar, realizar comportamientos al límite de lo honesto, como maquillar cuentas, no dar información cierta sobre los estados de cuenta de las sociedades, transformar las empresas las veces que sea necesario, siendo el leit motiv el ánimo de lucro en una sociedad de riesgos.

Las transformaciones de la empresa al socaire de los cambios en el modelo de producción, denominado post-fordista, en el que las empresas subcontratan partes de su propia producción, incluso a empresas extranjeras o trabajadores autónomos, dan lugar a una mayor diversificación del riesgo. Esto es particularmente evidente cuando hablamos de la moderna empresa en la sociedad de la información y en el mercado globalizado, donde la organización de la misma ya no es vertical-jerárquica como tradicionalmente lo ha sido, sino que se organiza en redes multidireccionales, la mayoría de las veces vinculadas a una gran empresa, donde las estructuras son altamente descentralizadas y muy flexibles de acuerdo a la flexibilidad de los mercados. ${ }^{3}$ Siguiendo la definición de CASTELls: ${ }^{4}$ "la «empresa horizontal" es una red dinámica y estratégicamente concebida de unidades autoprogramadas y autodirigidas basadas en la descentralización, la participación y la coordinación”. Es decir, el modelo organizativo propiciado por el cambio tecnológico y las nuevas necesidades de un mercado muy competitivo y cambiante, donde los riesgos se diversifican en la red, ya no se define como un conjunto de medios orientados a unos fines comunes, sino que la empresa-red está constituida por un sistema de redes interconectadas, pero a la vez autónomas en sus fines.

Este modelo económico también ha servido para que la criminalidad organizada dé un salto cualitativo y se dedique a actividades "no tradicionales", como la utilización de la misma para el lavado de dinero o para proveerse de fondos ilícitos, con el objeto de seguir el ciclo económico de las ganancias mal habidas. El desarrollo del sistema empresarial, especialmente con la desregulación propia de la globalización, ha dado un paso más para el desarrollo de la connivencia entre criminalidad organizada y criminalidad de empresa. Corporate crime y organized crime se coluden bajo la fórmula de la empresa, en un mercado abierto de carácter internacional. El delito de blanqueo de capitales es aquel en el que

\footnotetext{
${ }^{3}$ Cfr. Castells, Manuel. La era de la información. La sociedad red, 2a. ed., Alianza Editorial, Madrid, 2001, vol. 1, pp. 201-254.

4 Ibidem, pp. 216 y 217.
} 
confluyen todas las ganancias ilícitas provenientes de los ilegalismos y la criminalidad organizada.

Ya SutheRland, en 1949, se dio cuenta de este símil entre la corporate crime y la organized crime, al definir el delito de "cuello blanco" como delito organizado, estableciendo el siguiente parangón entre el delito de "cuello blanco" y el robo profesional: primero, la delincuencia de las corporaciones al igual que la de los ladrones profesionales es persistente; una gran proporción de los delincuentes son reincidentes. Segundo, la conducta ilegal es mucho más extensa de lo que indican las acusaciones y denuncias. Tercero, el hombre de negocios que viola las leyes para regular los negocios generalmente no pierde su estatus entre sus asociados. Y, cuarto, los hombres de negocios generalmente sienten y expresan desprecio hacia la ley, el gobierno y el personal del gobierno. ${ }^{5}$

La corporate crime vive momentos de gloria. Como suele suceder cuando de capitalismo se trata, todo empieza en los Estados Unidos. Según datos publicados por la revista Fortune, "desde el 1 de enero de 1999 al 31 de mayo de 2002, los administradores de 1035 sociedades han «robado» más o menos 66.000 millones de dólares". Mientras los administradores se hacian con dicho botín, los inversores perdían el 70\%, el 90\% o todos sus ahorros; mientras las sociedades se hundían, los administradores se hacían "inmensamente, extraordinariamente, obscenamente ricos". ${ }^{6}$ Pero las cifras astronómicas vendrían después. Primero, en 2001, en el caso Enron pudieron percibirse las características de estos comportamientos: engaño en las cuentas, contabilidad creativa como fraude, avaricia desmedida, especulación financiera sin importar realmente los servicios que debían proporcionar, en clara connivencia con el poder político. ${ }^{7}$ Más tarde, la caída de Lehman Brothers en 2008 y sus consiguientes quiebras de bancos, empresas y países son buena muestra de lo que se ha dado en llamar "el surgimiento de nuevas amenazas globales y nuevas formas de inseguridad colectiva: la gran criminalidad económica", ${ }^{8}$ que amenaza con desestabilizar las instituciones políticas y descomponer el modelo del Estado del bienestar pactado después de la Segunda Guerra Mundial.

Las conductas que desencadenaron todas estas consecuencias económicas pueden caracterizarse por típicos comportamientos fraudulentos en los libros: sujetos activos y pasivos intercambiables, interés especulativo común, comporta-

\footnotetext{
${ }^{5}$ Sutherland, Edwin. El delito de cuello blanco, cit., pp. 261-264.

${ }^{6}$ Cfr. Foffanl, LUIGI. "Escándalos financieros y reformas penales: prevención y represión de las infracciones societarias en la era de la globalización", en Revista Penal, núm. 23, 2009, p. 33.

7 Cfr. Estefania, Joaquin. "El gran saqueo", El País, 3 de abril de 2011.

${ }^{8}$ FoffANI, LuIGI. op. cit., p. 34. Todo ello magistralmente narrado por el documental Inside Job, de Charles Ferguson (2010), en el que claramente se puede observar cómo la desregulación económica ha sido funcional a Wall Street, a los bancos, y los poderes públicos no han sido capaces de atajarla, incluso los gobiernos demócratas.
} 
mientos engañosos, ${ }^{9}$ pero lo que le da el plus de complejidad y opacidad para ser descubiertas es el hecho de haberse realizado en el ámbito de empresas, personas jurídicas o sociedades.

No hay duda de que la empresa (persona jurídica), sociedad anónima, es la fórmula económico-jurídica que ha sido útil para la realización de todas estas conductas, por ser el instrumento jurídico dúctil para sortear responsabilidades: división entre el capital social de la persona jurídica y el de los administradores, transformaciones de sociedades, opacidad en las cuentas, marketing engañoso, etcétera. Tampoco hay duda que, en muchos casos, se trata de comportamientos individuales que se aprovechan de esta fórmula jurídica para la realización de conductas fraudulentas. La corporate crime es la fenomenología criminal para la realización de estos delitos de cuello blanco de las sociedades. La situación de poder que caracteriza a la mayoría de sujetos que cometen delitos a través de sociedades refuerza estos comportamientos en una sociedad de riesgos y configura una serie de caracteres distinguibles: personas bien situadas social y económicamente, alto grado de impunidad, comportamientos adecuados socialmente, conductas que rozan los ilegalismos.

La delincuencia que trata este artículo desafía los conceptos tradicionales del derecho penal, por cuanto su estructura conceptual, la teoría del delito, ha sido diseñada para establecer la responsabilidad de comportamientos individuales, donde existe un reproche por conductas inaceptables socialmente y el sujeto activo suele ser una persona marginal. Pero no sólo desafía al derecho penal sino también a la criminología: ni las concepciones deterministas del delito a partir de carencias sociales ni las teorías psicológicas de la violencia servirían para explicar estas formas de criminalidad. Vamos a intentar desentrañar esas características especiales que hacen de la criminalidad de cuello blanco un fenómeno difícil de aprehender con el derecho penal.

\section{Entre lo legal e ilegal}

El derecho penal posee un carácter secundario; es el último recurso dentro de los mecanismos de control social formal. El carácter ilegítimo de la conducta ha de estar sancionado previamente por regulaciones previas en el ámbito económico. No cabe duda de que la desregulación económica que ha caracterizado el mercado mundial de los últimos tiempos ha convertido en "legales" muchas

\footnotetext{
9 Sobre los límites de lo relevante e irrelevante penalmente dentro de la actividad económica vid. Silva SÁnchez, JesúsMARIA (dir.). ¿Libertad económica o fraudes punibles? Riesgos penalmente relevantes e irrelevantes en la actividad económico-empresarial, Marcial Pons, Barcelona, 2003, passim.
} 
conductas que, por tanto, son aceptadas socialmente y, cuando no, admiradas. Los hechos que han desencadenado la crisis financiera actual, con las hipotecas subprime o las contabilidades creativas de las cuentas para cotizar más en la bolsa, o que la aerolínea Spanair siga vendiendo billetes hasta el mismo momento en que dejó de volar, con pasajeros en tierra, son buena cuenta de ello. Siguiendo con el reportaje que inicia este trabajo,

[...] el experto Graef Cristal, [quien] dirige una revista online dedicada a analizar los comportamientos de los ejecutivos, considera que el fenómeno de la crisis de las hipotecas subprime o basura se explica en gran parte por el sistema de remuneraciones instaurado por los bancos de inversión estadounidenses a sus ejecutivos, a quienes reparten el 50\% de sus beneficios. Los empleados de los mayores cinco bancos de inversión percibieron 66.000 millones de dólares en 2007; de ellos, 39.000 millones en bonus. Esta cifra arroja una retribución media de 353.089 dólares por empleado, según Bloomberg. Como su sueldo provenía directamente de lo que ganara la empresa, hincharon artificialmente las cuentas, comercializando piramidalmente fondos $\mathrm{u}$ otros instrumentos financieros respaldados por los ahora llamados activos tóxicos. ${ }^{10}$

Es decir, no es que se trate de casos aislados que han surgido en alguna gran empresa; se trata de comportamientos organizados desde las permisiones regulativas que, en aras de la desregulación, no intervienen en la economía para favorecer la libre circulación de capitales. Algo similar sucede con los paraísos fiscales, lugar hacia donde confluye el lavado de dinero. Este es un ejemplo de las sofisticadas operaciones de blanqueo de capitales detectadas por el SEBPLAC:

[...] sociedades constituidas en paraísos fiscales transfirieron desde el extranjero grandes sumas de dinero a cuentas de grupos de sociedades españolas de reciente constitución, sin actividad hasta este momento, administradas por testaferros. Las transferencias se instrumentalizaron como préstamos concedidos a las sociedades españolas, y se aplicaron a inversiones de proyectos inmobiliarios. Más tarde las propiedades inmobiliarias se vendieron y el precio obtenido comenzó a ser transferido de nuevo a su punto de origen en concepto de devolución de los préstamos, tratando de conseguir desvincularlos de su origen ilegal. En otras ocasiones, los fondos permanecen en España, en la creencia de que ya han quedado desvinculados de su origen ilegal. Generalmente, se transfieren a cuentas particulares o de sociedades instrumentales, o se destinan a la adquisición de bienes inmuebles. ${ }^{11}$

En este supuesto se puede observar la complejidad de la maniobra y la dificultad para detectar la comisión de delitos. Intervienen personas físicas, personas jurí-

\footnotetext{
10 "Culpables, millonarios e impunes", op. cit., p. 10.

1 Vid. "El pozo negro de la economía sumergida", El Pais, 17 de enero de 2006, p. 13.
} 
dicas, bancos, sociedades inmobiliarias, testaferros, cuentas extranjeras, paraísos fiscales, dinero proveniente de algún delito, préstamos, inversiones inmobiliarias, etcétera. Así, dentro de una misma operación existen dificultades para deslindar lo legal de lo ilegal.

La penetración de la criminalidad organizada en la economía legal y la criminalidad de empresa que realiza comportamientos de blanqueo de capitales muestran las delgadas líneas de acercamiento entre ambas formas de criminalidad, donde la díada legal e ilegal otrora fundamental para comprender los fenómenos criminales ha perdido capacidad de explicación. Como sostiene PoNT1 ${ }^{12}$ al estudiar la criminalidad organizada que se ha infiltrado en el ámbito empresarial, la criminología estaba cómoda cuando tenía que conocer una realidad criminal en la que las fronteras entre legalidad e ilegalidad estaban claras, como sucede con el homicidio o la violación, pero ahora que se enfrenta ante verdaderos poderes, que utilizan herramientas legales para actuar, no posee herramientas conceptuales.

\section{3. ¿Es un delito el delito de cuello blanco?}

Es el título de uno de los capítulos del libro de Sutherland que podemos ahora incluso volver a plantear dadas las percepciones sociales que, al parecer, posee la ciudadanía sobre esta clase de delincuencia. ${ }^{13}$ Después de estudiar una serie de infracciones cometidas por las corporaciones, SUTHERLAND plantea el siguiente problema: "desde el punto de vista de la teoría de la conducta delictiva, ¿son los actos ilegales de las corporaciones, que se titularon anteriormente, análogos a los hurtos, robos y otros delitos que se incluyen corrientemente dentro de los límites de la conducta delictiva?". ${ }^{14}$ Cuestión que se plantea ante las dudas de configurar como delito los comportamientos que son meros ilegalismos realizados en los negocios, pero que producen gran daño social, como "las restricciones al comercio, la falsa representación publicitaria, la infracción de patentes y derechos y las prácticas laborales injustas, en violación de la ley Nacional de Relaciones

44 Laborales". ${ }^{15}$ El mismo autor, más adelante, responde a la pregunta planteada:

\footnotetext{
12 Ponti. "Criminalità organizzata e criminología", op. cit.

${ }^{13}$ Me refiero, claro está, al juzgamiento del caso Camps, en el que un jurado popular, pese a haber presenciado en el juicio oral que el ex presidente de la Comunidad Valenciana había sido obsequiado con trajes por parte de sujetos de la trama Gürtel, regalos no hechos a título personal sino por su situación de poder, siendo por tanto la punta del iceberg de una trama de corrupción, dio un veredicto desfavorable para su acusación por el delito de cohecho. Pero también ha de entenderse como una percepción social muy relativa del carácter antijurídico de la corrupción cuando sujetos imputados por estos delitos obtienen mayoría absoluta en las elecciones.

${ }_{14}$ Sutherland. El delito de cuello blanco, cit., p. 88.

15 Ibidem, p. 87.
} 
La característica esencial del delito es que es una conducta prohibida por el Estado como daño a ese Estado y contra el cual el mismo debe reaccionar, al menos como último recurso, por medio del castigo. Los dos criterios abstractos, generalmente considerados por los estudiosos legales como elementos necesarios en una definición de delito, son la descripción legal de un acto como socialmente dañino y la provisión legal de una pena para ese acto. ${ }^{16}$

Por supuesto, la respuesta a la cuestión planteada depende de la teoría de la conducta delictiva que se utilice. Desde un punto de vista positivista sólo sería delito aquella conducta descrita por la ley, y varios de los comportamientos arriba descritos no están tipificados como delitos, o sólo lo han sido muy recientemente, como sucedió con el delito de tráfico de influencias o administración desleal, por ejemplo. No obstante, ya en la década de los noventa, buena parte de las infracciones económicas han pasado a considerarse delitos al quedar tipificadas en el nuevo Código de 1995. Es decir, el legislador español, al igual que sus homónimos del entorno cultural, ha dado el paso de tipificar las infracciones económicas graves en el corazón de la legislación penal.

Así, más allá de la discusión de los años noventa sobre la legitimidad de los delitos económicos, existe un consenso general en la doctrina de la relevancia penal de las conductas que protegen determinados bienes jurídicos de carácter social o colectivo, esto es, de la dañosidad social de estos comportamientos y del merecimiento y necesidad de pena, aunque se hayan señalado algunas dificultades en las técnicas de tipificación, como la indeterminación de los tipos penales, el abuso de la técnica de la ley penal en blanco, la proliferación de delitos de peligro incluso en abstracto, etcétera.

Ahora bien, la interpretación de las normas jurídicas discurre dentro de unos parámetros culturales. Es lo que MAYER denominaba "las normas de cultura" que hay detrás de cada tipo penal. Pues bien, la aplicación de los tipos penales corresponde a una serie de instancias de control, por los que pasa por diversos tamices el supuesto de hecho considerado típicamente como delito hasta llegar a imputársele al autor un castigo. Es lo que la criminología crítica denominó la selectividad penal. Visto el delito desde el ámbito más amplio de su incardinación en el sistema de control social, ha sido esta teoría la que ha puesto el acento sobre el proceso de definición de delito. La criminalidad no se considera como una cualidad ontológica de determinados comportamientos y determinados individuos, no es una cuestión de estructuras lógico-objetivas ni de caracteres de las personas, sino más bien se trata de un status (un etiquetamiento) asignado

\footnotetext{
16 Ibidem, p. 89. Los subrayados son del autor.
} 
desde el poder. El enfoque de estudio se desplaza así del comportamiento desviado, tradicionalmente considerado como "patológico", "anormal”, en definitiva "criminal" (con la carga de simbolismo que ello conlleva), a los mecanismos de control social del mismo que se consideran "no neutrales", y en particular al proceso de criminalización, que es donde se selecciona qué comportamientos y qué sujetos ingresan en el sistema penal. ${ }^{17}$

La criminología crítica, al utilizar el método de análisis de las teorías del etiquetamiento y de las subculturas a las poblaciones carcelarias, puso de relieve el carácter desigual del derecho penal. Esto es, no todos los sujetos tienen la misma probabilidad de ser objeto de definición penal. La criminalidad es, desde los postulados de la criminología crítica, como lo manifiesta BARATTA: “«un bien negativo" distribuido desigualmente según la jerarquía de los intereses fijada en el sistema económico y según la desigualdad social de los individuos". ${ }^{18}$ Desde estos postulados se puede entender mejor por qué los comportamientos criminales cometidos por los poderosos no son considerados "delitos", o no tienen el estigma o la carga social negativa que poseen los comportamientos propios de la delincuencia callejera. 0 , dicho de otro modo, suele considerarse "delito" y "criminal", con la carga negativa que ello conlleva, los comportamientos realizados por los sectores marginales, porque el poder de definición lo ostentan en la sociedad los poderosos. Son éstos quienes a través de los medios de comunicación, de las estructuras sociales, tienen la capacidad de configurar los mapas mentales de la mayoría de las personas y, por supuesto, pueden lograr criminalizar o descriminalizar determinadas conductas en el Parlamento. ${ }^{19}$

El poder, que en la sociedad capitalista lo ostentan quienes poseen el capital, viste, limpia, descriminaliza ante el imaginario colectivo, como la prensa, los policías, los jueces y fiscales, que son los que en definitiva van a aplicar las leyes. Por ello es difícil someter a la delincuencia económica a los mismos parámetros que la delincuencia callejera. Como sostiene Quintero: "la delincuencia económica se presentó como parte del propio sistema, insometible a los mismos principios que esta otra, intratable con las mismas penas [...] sería absurdo esperar

17 Cfr. Baratta. "Criminologia y dogmática penal. Pasado y futuro del modelo integral de la ciencia penal", en Papers. Revista de Sociología, 1980, pp. 17 y ss. Vid., también, BaRATtA, Criminología critica y crítica del derecho penal, Siglo XXI, México, 1986, p. 167; PAvARINI, Control y dominación. Teorías criminológicas burguesas y proyecto hegemónico, trad. de Muñagorri, Siglo xxı, México, 1983, p. 147; Bustos. "Criminología crítica y derecho penal", Control social y sistema penal, PPU, Barcelona, 1987, p. 17; TAYLoR et al. La nueva criminología. Contribución a una teoría social de la conducta desviada, Amorrortu, Buenos Aires, 1977, p. 284.

${ }_{18}$ BaratTA. "Criminología crítica y política penal alternativa", en RIDP, núm. 1, 1978, p. 46.

19 Particularmente evidente ha sido en la Italia de Berlusconi; con el monopolio de los medios de comunicación y el manejo de las mayorías en el Parlamento consiguió descriminalizar delitos económicos que él mismo realizaba, o acortar los plazos de prescripción. La existencia de lobbys para la determinación de las leyes es también bastante conocido. 
que el bloque dominante se volviera contra sus propios miembros, sometiéndoles a un sistema represivo generado para otros". ${ }^{20}$

¿Por qué van a querer infringir las normas aquellos que lo tienen todo? Sólo los marginados de la sociedad pueden querer arrebatar a los demás sus bienes. GeIs se ocupa de la motivación del delito de cuello blanco:

Como sucede con la mayoría de conductas criminales, la suya es llevada a cabo para lograr algo que desean, algo que creen que no puede ser obtenido legalmente, al menos no sin un grado de dificultad, aunque el desafío y la euforia también pueden ser factores de motivación... Una ventaja considerable de contar con una determinada posición y con poder consiste en que éstos permiten a su poseedor infringir la ley de modos más refinados que los disponibles a los ciudadanos de a pie, especialmente para aquellos que de algún modo se hallen desposeídos o enajenados [...] La observación más común sobre el delito de cuello blanco cometido por parte de aquellos que parecen estar tan acomodados que no necesitan infringir la ley, es que su motivación es la avaricia. ${ }^{21}$

El documental Inside Job, de Charles Ferguson, cuenta claramente todo el proceso de desarrollo de la Gran Recesión actual, desde la desregulación económica de la era Reagan-Thatcher (que profundizó el demócrata Clinton), hasta el estallido de las hipotecas subprime y la caída de bancos, agencias de calificación y grandes empresas. Con una narrativa cinematográfica que imprime un ritmo frenético así como fueron las ganancias, el documental muestra cómo los directivos de las grandes empresas iban acumulando ganancias, bienes, lujos, como jets privados, apartamentos en Manhattan, todo era poco para saciar la avidez de las ganancias. Para ello contaron con los lobbys desreguladores; analistas corruptos; agencias de calificación compradas; productos derivados opacos, calificados como "armas de destrucción masiva"; amenazas a los legisladores, y pagaron a expertos académicos "independientes" de la Universidad de Harvard para fomentar un sistema de depredación. La avaricia, como pecado capital, es la motivación que se observa en estos negocios que, como la droga, anima a tener cada vez más sin importar cómo, ni cuáles son las consecuencias de sus actos. ${ }^{22}$

\footnotetext{
${ }^{20}$ Quintero Olivares, Gonzalo. "Economía e instrumentos represivos", en Papers. Revista de Sociología, núm. 13, 1980, p. 197.

${ }^{21}$ GeIS, GILBert. "El delito de cuello blanco como concepto analítico e ideológico", en Bueno Arús et al. (dirs.). Derecho penal y criminología como fundamento de la politica criminal. Estudios en homenaje al Prof. A. Serrano Gómez, Dykinson, Madrid, 2006, p. 320.

${ }^{22}$ Interesante es este extracto del guión del film, escrito por Charles Ferguson y coescrito por Chad Beck y Adam Bolt (p. 34):

"Jonathan Alpert: These people are risk-takers, they're impulsive.

(Jonathan Alpert is a therapist whose clients include many high levels Wall Street executives)
} 
Ahora bien, ¿por qué va a ser pecado si el sistema capitalista está organizado para fomentar las ganancias?, ¿dónde están los límites entre la especulación lícita e ilícita?

Una dificultad para el tratamiento de estos delitos es, precisamente, que no se tiene conciencia social de la ilicitud de los comportamientos, porque como ya se ha dicho, muchos comportamientos de los negocios se encuentran en la frontera de lo permitido. No la tienen los propios sujetos que los realizan ni la ciudadanía en general, que no percibe el daño social que causa este tipo de criminalidad.

\section{La percepción social de la criminalidad de los poderosos}

La configuración social de lo que es delito y a quiénes consideramos responsables para la imposición de penas, como el castigo mayor de la sociedad, no pasa solamente por las tipificaciones penales; detrás de ellas existe una serie de variables sociales, como valores, creencias, estereotipos, formas de reaccionar frente a los comportamientos desviados y una red de instituciones y conceptos que denominamos control social. Se trata de una serie de mecanismos, formales e informales, que establece los límites de los comportamientos y determina las respuestas a esos comportamientos por parte del cuerpo social. Este proceso, que en muchos casos es sutil, como la educación en la infancia o en los propios medios de comunicación, va configurando mentalmente aquello que se considera admitido y prohibido, aceptado o inaceptable. Así, aunque algunas normas tipifiquen determinadas conductas como delito, a veces existen fuerzas sociales que las reducen a la inaplicabilidad, como sucedió con los delitos de insumisión o como pasa, aun ahora, con el aborto consentido.

En buena medida es lo que ocurre con los delitos económicos, especialmente aquellos vinculados con la corrupción política y la corrupción privada, que no poseen el mismo reproche social que los delitos callejeros. El sistema de control social puede visualizarse como una pirámide, como hace algunos años apuntaba MuÑoz Conde, donde en la cúspide está el derecho penal; mejor aún, puede

\footnotetext{
It's part of their behaviour, it's part of their personality. And that manifests outside of work as well.

It's quite typical for the guys to go out, to go to strep bars, to use drugs. I see a lot of cocaine use, a lot of use of prostitution.

(The owner of the v.I.P. club in Chelsea, who estimates that about 80 per cent of this clients are wall street types)

(ANDREW Lo, professor \& director MIT laboratory for financial engineering)

ANDREw Lo: Recently, neuroscientists have done experiments where, uh, they've, uh, taken individuals and put them into an MRI machine. And they have them play a game where the prize is money. And their noticed that when these subjects earn money, the part of the brain that gets stimulated is the same part that cocaine stimulates".
} 
realizarse el símil del iceberg, donde aquello que puede observarse es sólo una punta del bloque de hielo realmente existente. Dentro del sistema de normas y mecanismos para asegurar las pautas de conducta del grupo, la sanción social es normalmente la primaria y más contundente reacción social ante un comportamiento prohibido, porque cotidianamente los ciudadanos están en relación con sus congéneres y no con las normas. Son las personas que rodean a quienes realizan los comportamientos desviados quienes les dan el mensaje de la conformidad o no del comportamiento a lo esperado socialmente.

Esta cuestión es extremadamente importante para la persecución penal de la delincuencia económica que tratamos, dado que explica la legitimidad social del propio delito de cuello blanco y, por consiguiente, de la deslegitimación del derecho penal cuando no es capaz de prevenir los comportamientos.

El catedrático de Criminología de la Universidad Estatal de Pensilvania, Richard Ball, se ha ocupado especialmente del tema. Ball sostiene que:

[...] el delito de cuello blanco ha pasado a ser aceptable en muchas organizaciones (Coleman, 2002). En parte porque los delincuentes de cuello blanco son personas con una formación mayor que la de la mayoría de los delincuentes y mucho más preocupados por su "respetabilidad" [...] A veces la legitimación procede de la propia sociedad [...] como Estados Unidos, por ejemplo, estos delitos mencionados están basados en parte en el espíritu general que ensalza las virtudes de una competencia fuerte. ${ }^{23}$

Por tanto, no es de extrañar la actualidad del trabajo de SutHerLAnd, quien en la década de los años treinta ideó la teoría de la asociación diferencial, poniendo en evidencia que en cuanto a los delitos cometidos por las corporaciones, "la conducta delictiva se aprende en asociación con aquellos que definen la conducta favorablemente y en aislamiento de aquellos que la definen desfavorablemente". ${ }^{24}$ En efecto, existe un refuerzo positivo entre los propios miembros del grupo en el que se realizan los delitos económicos y, lamentablemente, ese refuerzo positivo se ha trasladado a la sociedad en general. Veamos por separado estos dos enunciados.

BALl, con la teoría general de sistemas (TGS), estudia cómo sucede este proceso de legitimación dentro de la propia organización:

La TGS insiste en que las organizaciones tienen sus propias propiedades independientes de los empleados que comprenden, y en que estas propiedades están constituidas

\footnotetext{
${ }^{23}$ BALL, Richard A. "El enfoque de la teoría general de sistemas aplicado a los delitos organizacionales de cuello blanco", en Bueno Arús et al. (dirs.). Derecho penal y criminología como fundamento de la política criminal..., cit., p. 122.

24 SutherLand, Edwin. El delito de cuello blanco, cit., p. 277.
} 
tanto por la estructura de la organización como por la naturaleza de las relaciones que establece entre los empleados [...] Por ejemplo, existen muchas pruebas de que las grandes organizaciones como las sociedades anónimas funcionan mediante una ampliación de los mecanismos psicológicos de defensa individuales, como la negación, la despersonalización, el aislamiento de la afectación y la compartimentalización ética, junto con una represión de otras características como la preocupación por la ética personal contraria a la organización. De este modo "reconstituyen" a los empleados. ${ }^{25}$

Podría decirse que ésta es una generalización, que existen organizaciones donde no funciona así, claro está. La cuestión es que a los efectos de estudiar la proliferación de los delitos económicos y su negación por parte de la sociedad, conviene no olvidar ese refuerzo positivo en cuanto a valores, formas de proceder que discurren puertas adentro de las organizaciones y que propician dichos delitos. Suelen ser formas de actuar incluso imperceptibles por los propios miembros del grupo en tanto están "normalizadas"; de ahí la inexistencia de una conciencia sobre la ilicitud de la conducta, cuyas formas de actuar están reforzadas hacia fuera por la cultura, como la cultura de la competencia, la idea de que es un "triunfador" quien posee determinados bienes; que a veces para ganar hay que arriesgar, incluso al límite de lo ilícito; que todas las personas tenemos un "precio"; la flexibilización de la moralidad; la carencia de valores, etcétera. Como anota BAll,

[...] lenta y sutilmente van excediendo los límites de las prácticas aceptables hasta ser finalmente "normalizadas". Ello se lleva a cabo en ocasiones a través de "técnicas de neutralización” que proporcionan excusas para "neutralizar" las normas jurídicas en determinadas circunstancias, mientras continuamos acogiéndonos a ellas en abstracto. Estas excusas incluyen la negación de la responsabilidad, la negación de daños, la negación de la víctima, la condena de los condenadores y la apelación a lealtades más elevadas. ${ }^{26}$

50 El otro enunciado que corresponde desarrollar es cómo esa percepción de normalización o comportamiento neutral de los delitos de cuello blanco ha traspasado a toda la sociedad. En primer lugar está la cultura en la que vivimos, que, como se ha dicho, premia a quien tiene poder y dinero, y al relativizarse los valores, no importa cómo se obtienen. Se considera un triunfador o un ga-

\footnotetext{
25 Ball, Richard A. "El enfoque de la teoría general de sistemas aplicado a los delitos organizacionales de cuello blanco", op. cit., p. 123.

26 Idem.
} 
nador a quien posee bienes en propiedad; por el contrario, un perdedor, ocioso, marginal, es quien no es capaz de trabajar para ganar y adquirir bienes. He ahí el trasfondo del doble tratamiento penal de la delincuencia de cuello blanco y la delincuencia marginal por parte de la política criminal moderna que despenaliza los comportamientos de los primeros y demanda rigor para los segundos. El lento pero inminente cambio del control social centrado en la resocialización hacia la retribución, magistralmente analizado por GARLAND, está asimismo en el trasfondo de esta doble vara de medir esas dos clases de criminalidad, pues las políticas de tolerancia cero sólo se han aplicado para la delincuencia marginal. La explicación está en los marcos conceptuales que mayoritariamente han sido instalados en la sociedad.

El catedrático de lingüística y ciencias cognitivas de la Universidad de California, George LAKOFF, define los frames o marcos como "las estructuras mentales que le permiten al ser humano entender la realidad $y$, a veces, crear lo que entendemos por realidad [...] Los marcos facilitan nuestras interacciones más básicas con el mundo: estructuran nuestras ideas y nuestros conceptos, conforman nuestra manera de razonar e incluso inciden en nuestra percepción y en nuestra manera de actuar." ${ }^{27}$ Los marcos conceptuales se instalan en el inconsciente y nos sirven para interpretar la realidad. Los marcos definen el "sentido común” y configuran la opinión pública. El mismo autor señala: "los conservadores han conseguido cambiar el "sentido común" y los progresistas les han dejado hacerlo". ${ }^{28} \mathrm{El}$ admitir una tolerancia social importante para los delitos cometidos por los poderosos es un gran logro de los sectores interesados en ello. Mientras los sectores conservadores han conseguido atraer la atención frente a fenómenos criminales callejeros, violentos, la gran criminalidad económica posee millones de dólares en sus bolsillos. El centrar la cuestión de la responsabilidad penal como un tema individual y no social es otro gran logro. Asimismo, el focalizar todos los problemas sociales, como la criminalidad, en una cuestión de pérdida de valores familiares es un gran leit motiv de los sectores conservadores que permite distraer las verdaderas causas, como son las pérdidas de empleo, la inseguridad de los mismos y, especialmente, la caída de los salarios de los trabajadores en los últimos años. ${ }^{29}$

\footnotetext{
${ }^{27}$ Lakoff, George. Puntos de reflexión. Manual del progresista, Península, Barcelona, 2008, p. 56.

28 Ibidem, p. 74.

${ }^{29}$ Krugman. "Dinero y moralidad", El País, 12 de febrero de 2012, p. 21. Este Premio Nobel nos ilustra cómo "Murray y otros conservadores tienden a dar por sentado que el declive de la familia tradicional tiene repercusiones terribles para la sociedad en su conjunto". Esta visión del problema esconde qué está sucediendo con la familia de la clase trabajadora, que ha visto reducidas drásticamente sus oportunidades de empleo y sueldo en los últimos años. Se estima que el salario de los trabajadores con bajo nivel de estudios ha caido un 23\% desde 1973 en los Estados Unidos.
} 
En segundo lugar, la sociedad no percibe la dañosidad social de estos comportamientos. Un ingrediente importante en esa aceptación o cuando menos benignidad en el tratamiento de la criminalidad cometida por los poderosos es la falta de conciencia social de los daños que produce. La ciudadanía no es capaz de percibir conexiones entre esa gran criminalidad que encuadra este trabajo y la crisis económica actual, con la consiguiente pérdida de puestos de trabajo, que rebaja el nivel de vida y provoca la inseguridad social, seguramente porque no hay relación causa-efecto lineal y se necesita investigar mucho para ubicar las conexiones. Como sostiene Martínez-Buján, el ciudadano medio no tiene conciencia de la gravedad de la criminalidad socioeconómica y sucede precisamente lo contrario que con la criminalidad callejera: aquí el riesgo objetivo es mucho mayor que la sensación subjetiva. Y precisamente una de las causas de la insuficiente represión de los delitos económicos estriba en su supuesta "neutralidad" o apariencia de "licitud". ${ }^{30}$

En tercer lugar, esta visión benigna de la gran criminalidad económica está continuamente reforzada por los medios de comunicación. Por supuesto que esta tolerancia social frente a la criminalidad económica no podía llevarse a cabo si no fuera por la caja de resonancia de los medios. LAKoff analiza cómo los marcos conceptuales se configuran con ideas simples y a base de repetir insistentemente las mismas; por tanto, los medios de comunicación adquieren suma importancia para la configuración de dichos marcos. Si la determinación cultural de lo que entendemos por delito y a quiénes exigimos responsabilidad penal es un proceso configurado dentro de las instancias de control social, los medios de comunicación (televisión, prensa, Internet, etcétera), en la sociedad de la información, son los encargados de construir y reforzar esos marcos conceptuales.

Últimamente se ha prestado atención al papel de los medios de comunicación en la política criminal, toda vez que los temas penales concitan gran parte de la información que se da cada día a la ciudadanía. Como explican Botella y PérezNeто, "los medios de información tienen una importancia crucial, al atraer la atención sobre determinados procesos, al fomentar una percepción más o menos morbosa de los mismos y al sugerir elementos de análisis y respuestas sociales ante fenómenos complejos". ${ }^{31}$ Interesa resaltar la atracción de la atención de los medios sobre determinados procesos criminales de carácter violento y vinculados

\footnotetext{
${ }^{30}$ Martinez-Buján, Carlos. "Reflexiones sobre la expansión del derecho penal en Europa con especial referencia al ámbito económico: la teoría del «big crunch» y la selección de bienes jurídico-penales", en MiR Puig y CoRcor BIDAsolo (dirs.). La politica criminal en Europa, Atelier, Barcelona, 2004, p. 100. En efecto, aún hoy algunos de los operadores jurídicos no son capaces de asociar delincuencia con otro tipo de personas que no sean los marginales de la sociedad. 31 Botella, JoAn y Pérez-Neto, LuIS. "La formación de la opinión pública y la construcción de discursos sobre la realidad criminal", en Garcia Arán y Botella (dirs.). Malas noticias. Medios de comunicación, política criminal y garantías penales en España, Tirant lo Blanch, Valencia, 2008, p. 47.
} 
a delitos contra la vida y la propiedad, lo que en ciencias de la comunicación se denomina teoría de la agenda setting. Es la idea de que "existe una transferencia de relevancia de los temas presentados en la agenda de los medios hacia la agenda pública y la agenda política". ${ }^{32}$ Esto es, los tipos de criminalidad que presentan los medios, la insistencia, las posibles respuestas que apuntan frente a ellas, no son cuestiones neutrales. El punitivismo expresado por la opinión pública, las demandas de ley y orden o políticas de tolerancia cero frente a los delitos contra la vida y la propiedad, principalmente, son en buena manera inducidos por las representaciones de amenazas que configuran los medios. Particularmente evidente fue la campaña contra los robos violentos en residencias, que desencadenó reformas penales de aumentos de penas, no congruentes con el grado real de criminalidad existente en nuestro país. ${ }^{33}$ Conseguir la empatía con las víctimas suele ser la estrategia de estas formas de comunicación de la criminalidad. Precisamente, víctimas poderosas y ricas. Y, mientras tanto, los delitos cometidos por los poderosos y ricos no logran un lugar en la agenda setting, al menos al mismo nivel de insistencia que esa clase de criminalidad.

\section{La impunidad de los delitos de cuello blanco}

No extraña, pues, que en estas formas de criminalidad que tratamos exista una gran cifra negra, que muchos casos no lleguen a perseguirse penalmente y aunque se persigan no concluyen en condenas, y si se condena, no se imponen penas de cárcel. Si observamos la cantidad de delincuencia económica que aparece en los medios y los tipos de delitos de los sujetos que llegan a la cárcel, podemos verificar que la realidad de la persecución penal de estos delitos es bastante selectiva. La selectividad penal es particularmente evidente en los delitos de cuello blanco, por los diversos factores anteriormente enunciados: inexistencia de la ilegalidad clara de algunas conductas, falta de conciencia de los ilícitos, refuerzo positivo dentro del propio grupo, tolerancia de su tratamiento en la sociedad y, por consiguiente, por parte de los operadores jurídicos encargados de aplicar las normas.

Además, la fórmula persona jurídica o societaria ha facilitado la comisión de delitos económicos, diluyendo la responsabilidad personal en el engranaje de las organizaciones, permitiendo las transformaciones de las mismas e incluso la exis-

\footnotetext{
32 Garcia Arán, Mercedes y Pérez-Neto, Luis. "Perspectivas de análisis y principios constitucionales", en Garcia Arán y Botella (dirs.). Malas noticias..., cit., p. 28.

33 Vid. sobre este tema Rebollo, Rafael. "Oleadas informativas y respuesta político-criminal (a propósito de los robos en residencias)", en Garcia Arán y Botella (dirs.). Malas noticias..., cit., pp. 67 y ss.
} 
tencia ficticia de sociedades fantasmas para la realización de los mismos. No es descabellado realizar la siguiente ecuación: fórmula empresarial persona jurídica + sujetos bien situados social y económicamente $=$ altos índices de impunidad. Los escándalos financieros y políticos que se han visto en diferentes países como Estados Unidos, España o ltalia, son buena muestra de esta criminalidad del poder, en la que en el centro encontramos fórmulas empresariales. Como bien recuerda Álvarez URía,

[...] gracias a los trabajos de SUTHERLAND conocemos mejor la mecánica que facilita la impunidad de los delincuentes de cuello blanco. Los grandes procesos de estos delincuentes presentan la apariencia de la singularidad que les otorga el prestigio social del acusado pero en realidad no pueden ser más repetitivos y rituales. En un primer momento el presunto delincuente, cuando se produce la orden de detención, se declara inocente y víctima de una maquinación. Como se creen situados en el centro del mundo, confunden su caída con la caída del mundo. Unos, los más débiles, formulan en voz alta el chantaje: si me detienen tiraré de la manta. Otros, los que cuentan con más apoyos, guardan un significativo silencio. Saben que sus amigos no cesarán de actuar en la sombra [...]..$^{34}$

La prevención de esta clase de comportamientos fraudulentos que se aprovechan del libre cambio y utilizan la fórmula empresarial de persona jurídica, constituye una de las tareas actuales más desafiantes de la política criminal, que plantea, sin duda, un programa de intervención complejo pluridimensional. De esta manera, existe consenso en que seguramente ha de idearse una serie de mecanismos de intervención: administrativo, civil, mercantil, pero también penal. Y en este ámbito, sólo la intervención penal en ambas dimensiones, de la responsabilidad penal individual y la responsabilidad penal de la empresa, puede ser capaz de hacer frente a la complejidad de los delitos cometidos en el ámbito empresarial.

Ciertamente que el castigo a las empresas no impide la proliferación de estos comportamientos individuales fraudulentos, pero al menos ha de reconocerse que, siendo la fórmula idónea para la maquinación y realización de todos ellos, su intervención obstaculiza la utilización de una herramienta fundamental en esta fenomenología criminógena y, por tanto, estrangula las posibilidades de su realización.

Las propuestas más modernas inciden especialmente en este aspecto para rediscutir la cuestión de la responsabilidad penal de las personas jurídicas. La empresa como agente económico y social, que ocupa un lugar fundamental en la sociedad postindustrial, ha de tener derechos, pero también deberes, entre los

34 Álvarez-Uria, Fernando. "Prólogo", op. cit., p. 48. 
cuales se incluye la responsabilidad penal (y la protección jurídica vinculada a ésta). ${ }^{35}$ 0, como apunta Voget: "el precio que debe pagarse por el liderazgo es, claro está, la responsabilidad (responsibility) [...] un pragmatismo cada vez más extendido puede referirse a que las sanciones penales deben ser aplicadas como mecanismo eficaz para conseguir que las normas sean también respetadas en la economía y también frente a los agentes económicos, los empresarios y las empresas" ${ }^{36}$ Existe una necesidad de encauzar jurídicamente la ética del merca$\mathrm{do}^{37}$ por medio de la demanda social de responsabilidad de la empresa, dentro de la cual, la responsabilidad penal no puede ser sustraída.

En este contexto de aperturas, de capitalismo sin responsabilidades, de Estados mínimos que no son capaces de cubrir las necesidades de sus ciudadanos, la violencia desorganizada y las mafias campan a sus anchas, así como la criminalidad cometida por los poderosos. Como sostiene DAHRENDORF: "cuando se descubrió que la eliminación de las barreras también podía ponerse al servicio de fines perversos y hasta destructivos, ya era demasiado tarde". ${ }^{38}$ Los flujos de capitales han desvelado una economía criminal que discurre soterradamente, incluso emparentada con la economía legal. ${ }^{39}$ Los dictados de la razón económica sobre la razón moral y política han sabido imponer, como una realidad cruel, el mundo del crimen organizado y de la gran criminalidad económica. Son, sin duda, las amenazas actuales a la seguridad mundial y, por tanto, a las actuales democracias. El crimen global es la "cara amarga" de la globalización en la que perdedores, descontentos, nihilistas, aprovechados, inmorales, consumistas de frutos prohibidos, avariciosos, se unen para lucrar ilícitamente en el tráfico mundial.

En este proceso de internacionalización de la empresa, ésta se ha convertido en un instrumento clave de la criminalidad organizada (criminalidad como empresa), vinculada a la criminalidad de empresa (criminalidad económica) y a la

\footnotetext{
${ }^{35}$ Cfr. VervaelE, John. "La responsabilidad penal de y en el seno de la persona juridica en Holanda. Historia y desarrollo reciente", El derecho penal europeo. Del derecho penal económico y financiero a un derecho penal federal, ARA Editores, Lima, 2006, p. 35.

${ }^{36}$ Cfr. Vogel, Joachim. "Responsabilidad penal de los empresarios y de las empresas", en Mir Puig y Corcor Bidasolo (dirs.). La politica criminal en Europa, cit., p. 130.

${ }^{37}$ Vid. desde esta óptica el estudio de De MAgLE, CRISTINA. L'etica e il mercato. La responabilità penale delle società, Giuffrè, Milán, 2002, passim, donde la autora resalta que las últimas reformas en materia de responsabilidad penal de personas jurídicas responden a la finalidad de racionalizar el mercado y la empresa.

${ }^{38}$ Dahrendorf, Ralf. En busca de un nuevo orden. Una política de la libertad para el siglo xxl, Paidós, Barcelona, 2005, p. 37.

${ }^{39}$ Precisamente la Unión Europea discute la posibilidad de contabilizar la economía ilegal en su afán de calcular la economía sumergida. Vid. "Narcotraficantes y chulos, pasen por caja", El País, 20 de abril de 2009. Las dificultades de tales cálculos son obvias, pero también las consecuencias jurídico-políticas de tal decisión. Parece incongruente luchar contra los paraisos legales y fiscales con contabilizar la economía criminal en la economía legal de los Estados. Es indudable un efecto "llamada" y de connivencia con el crimen organizado si contabilizamos sus ganancias como parte de la riqueza nacional.
} 
corrupción política, sin olvidar al terrorismo. En todos estos casos, la utilización de empresas, sociedades, asociaciones, en fin, personas jurídicas, es la fenomenología más usada para la realización de actividades ilícitas que lesionan bienes jurídicos reconocidos como fundamentales para la sociedad.

Pueden condensarse en dos tipos de razones las demandas político-criminales de sancionar penalmente a las empresas: razones de justicia y razones de eficacia. ${ }^{40}$ Dicho de otro modo, el modelo de la responsabilidad individual que ha prevalecido en los países de tradición eurocontinental, especialmente de ascendencia alemana, se ha mostrado injusto e ineficaz cuando los delitos se cometen dentro de la estructura organizativa de la empresa. ${ }^{41}$ Injusto porque, finalmente, los procesos penales recaían en una persona física en la que se "carga" toda la responsabilidad, ya sea el representante o el administrador de la empresa. Ineficaz porque la prevención de comportamientos delictivos que se suceden en el ámbito empresarial se muestra altamente limitado, debido a las dificultades de individualizar la responsabilidad penal, mismas que se convierten en imposibilidad cuando se trata de estructuras complejas.

Ciertamente, tanto el modelo de actuar en nombre de otro como el de responsabilizar al titular de la empresa, desarrollados por la doctrina y plasmados en la ley, se han mostrado altamente deficitarios, toda vez que el problema principal de individualizar responsabilidades cuando se cometen delitos desde organizaciones complejas no puede ser superado, consiguiendo finalmente soluciones desalentadoras: o se imputa el delito a unos determinados autores que no son necesariamente quienes reúnen todos los elementos del tipo objetivo y subjetivo, o se presentan lagunas de penalidad..$^{42}$ Ello conlleva la irresponsabilidad organizada denunciada hace tiempo por SHünEMAN, que se traduce en impunidad con el consiguiente déficit de prevención de los delitos económicos.

\section{A modo de conclusión: las dificultades en la persecución penal de los crímenes de los poderosos}

Se han podido analizar los factores culturales que existen en la sociedad actual que favorecen una comprensión de los delitos de cuello blanco mucho más be-

\footnotetext{
${ }^{40}$ Como bien sintetiza el especialista italiano De Simone, GuiıIo. "Autores del conflicto: autores y víctimas del delito", Manuale de diritto penale, parte generale, II Mulino, Bolonia, 2007, p. 293.

${ }^{41}$ Sobre los problemas jurídico-penales para la determinación de la responsabilidad penal en organizaciones empresariales véase Montaner, Raduel. Gestión empresarial y atribución de responsabilidad penal. A propósito de la gestión medioambiental, Atelier, Barcelona, 2008, passim.

42 Vid., más ampliamente, ZúÑIGa Rodriguez. Bases para un modelo de imputación de responsabilidad penal de las personas juridicas, cit., pp. 199-236.
} 
nigna que la criminalidad callejera. Existe prácticamente una visión atávica de la peligrosidad de la delincuencia violenta, callejera, contra la vida y la propiedad, pero aún no es capaz la ciudadanía de comprender la amenaza social que supone la criminalidad cometida desde los sectores poderosos: corrupción política, corrupción privada, criminalidad corporativa, criminalidad financiera, etcétera. La cultura de la competencia desenfrenada del modelo productivo actual y la desregulación económica favorecen comportamientos que rozan los ilegalismos y la criminalidad. La percepción social y de los propios infractores de que muchos de estos comportamientos no son "delito", porque están normalizados, impide una prevención cabal del derecho penal, puesto que éste es sólo el último recurso del control social, y los mecanismos más próximos a dichos comportamientos, siendo primarios y más eficaces en teoría, suelen fallar en la práctica, dada esa percepción social bastante generalizada de que "cualquiera en la misma situación también lo haría”. Los medios de comunicación también han contribuido a reforzar estos mapas conceptuales (frames), en los que los infractores dentro de sus propios grupos (llámese empresas, partidos políticos, etcétera) se sienten reafirmados por sus congéneres y fuera del grupo dada la aceptación social de la ciudadanía.

¿Cómo prevenir estos crímenes por parte del derecho penal cuando no existe un reproche social contundente de la ciudadanía? No es una cuestión fácil. El corrupto, como el mafioso, siempre encontrará incluso en su propia conciencia alguna justificación de su comportamiento, justificación que también aceptará cierta parte de la población, a veces beneficiaria del delito económico o de la actividad ilegal del poderoso. Se trata de seguir trabajando por parte de todas las disciplinas implicadas, la criminología, la dogmática, así como la legislación y la jurisprudencia, en la comprensión de esta forma de criminalidad que posee características distintas a las que ha sido la realidad tradicionalmente inducida por el derecho penal, los delitos de los sectores marginales, violentos, contra la vida y la propiedad. Como ha señalado SuTHERLAnd, se trata de "comprometerse en la búsqueda de una teoría del delito que sea a la vez explicativa y que concurra a prevenir los actos delincuentes" ${ }^{\prime 3}$ de los poderosos de cuello blanco, olvidados de los tradicionales estudios de derecho penal.

${ }_{43}$ Álvarez-Uria. "Prólogo", op. cit. 